Pendekatan Pemodelan Sistem: Proses Optimasi dan Pemanfaatan Mesin di Pabrik Produksi Menggunakan Model Simulasi Lean Manufacturing

\title{
A System Modelling Approach: Optimization Process and Machine Utilization in Production Plant Using Lean Manufacturing Simulation Model
}

\section{Ali Pahmi*}

*Program Studi Teknik Industri, Sekolah Tinggi Teknologi Muhammadiyah Cileungsi

*Jl. Anggrek No 25, Perum PTSC, Cileungsi, Bogor, Jawa Barat-Indonesia 16820

*Koresponden Email: ali.pahmi@sttmcileungsi.ac.id

\section{INFORMASI ARTIKEL ABSTRAK}

Histori Artikel

Artikel dikirim

06/09/ 2021

Perbaikan berkelanjutan, reduksi dan eliminasi waste dalam proses bisnis menjadi salah satu aspek yang dilakukan agar dapat terus memiliki daya saing yang sustainable. PT. X saat ini sedang dalam proses melakukan transformasi, reduksi dan eliminasi NVA serta perbaikan berkelanjutan di sisi proses guna meningkatkan daya saing yang sustainable. penelitian ini bertujuan dalam menganalisis dan mengajukan formulasi perbaikan proses menggunakan metode kerangka kerja pemodelan sistem dan simulasi. Temuan dari penelitian diketahui bahwa peningkatan Utilisasi Dies rata-rata $82,82 \%$ relative meningkat $36 \%$ dibanding simulasi sebelumnya $(52,9 \%)$; dengan rata-rata output $21,04 \mathrm{pcs} / \mathrm{jam}$ relative meningkat $42 \%$ dibanding simulasi sebelumnya $(12,9 \mathrm{pcs} / \mathrm{jam})$, hal ini dengan melakukan improvement proses semi auto dalam proses eject produk yang sekaligus berdampak dalam pengurangan manpower, serta mereduksi loss time akibat lama proses pendinginan dengan sistem heat transfer conveyor system

Kata kunci: System modelling, Utilization, Lean Manufacturing, Process Improvement

\begin{abstract}
Continued improvement, reduction and or elimination of waste in business processes is one aspect that is carried out in order to continue to have sustainable competitiveness. PT. $X$ is currently in the process of transforming, reducing and eliminating NVA as well as continuous improvement on the process side to increase sustainable competitiveness. This study aims to analyze and propose process improvement formulations using a system modeling framework method and simulation. The findings from the study showed that the increase in Dies Utilization was an average of $82.82 \%$, a relative increase of $36 \%$ compared to the previous simulation (52.9\%); with an average output of 21.04 pcs/hour, a relative increase of $42 \%$ compared to the previous simulation (12.9 pcs/hour), this is done by improving the semi-auto process in the product eject process which at the same time has an impact on reducing manpower, as well as reducing loss time due to the long cooling process with a heat transfer conveyor system.
\end{abstract}

Keywords: System modeling, Utilization, Lean Manufacturing, Process Improvement 


\section{Pendahuluan}

Penerapan efisiensi dan efektivitas proses produksi menjadi tujuan bagi setiap organisasi agar dapat bersaing di era perkembangan teknologi dan persaingan pasar yang semakin kompetitif. Berdasarkan laporan percepatan pemulihan ekonomi edisi 1/2021 yang diterbitkan oleh Kemenkeu RI[1][2], menyatakan terjadinya pandemi Covid-19 secara global menyebabkan berbagai industri besar dunia secara global mengalami kontraksi penurunan demand. Saat ini perusahaan dan organisasi saat ini mulai berpikir secara strategis bagaimana mereka berimprovisasi, beradaptasi dan menghadapi dampak pandemi dan tuntutan pasar yang semakin agile dan berkembang. Kondisi proses di plant produksi PT. X diketahui terdapat unbalanced out proses di area produksi, dimana hanya proses melting furnace yang mampu menyamai Takt time konsumen. Sehingga sebuah perubahan perlu dilakukan secara incremental dengan menerapkan optimalisasi proses di area casting. Penelitian ini bertujuan untuk menganalisis dan mengajukan formulasi perbaikan proses menggunakan metode kerangka kerja pemodelan sistem dan simulasi model.

Salah satu perubahan radikal dalam mencapai efisiensi dan efektivitas produksi dalam dunia industri yang cukup terkenal adalah metode dan filosofi Toyota Production System (TPS) atau Lean manufacturing yang diciptakan oleh Taiichi Ohno dan Eiji Toyoda [3]. Metode ini sangat dalam 14 prinsip TPS-nya dan umumnya digunakan pada industri manufaktur, khususnya otomotif untuk dapat mencapai kedua hal tersebut.

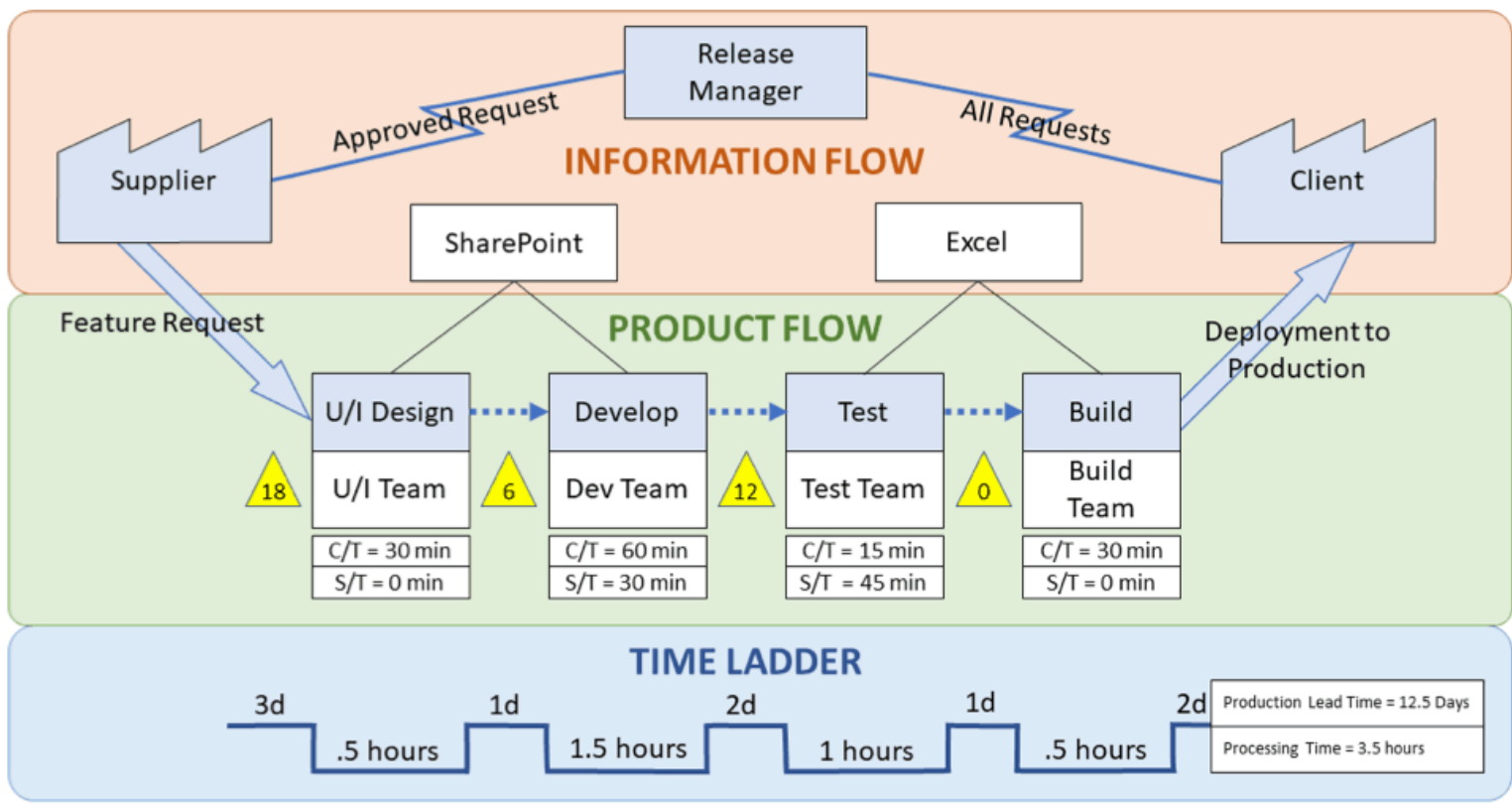

Gambar 1. Contoh model VSM (https://www.plutora.com/blog/value-stream-mapping)

Metode ini menekankan pada konsep bahwa adanya dua pilar utama dalam mencapai tercapainya QCDSE dan level world class manufacturing, yaitu Autonomous maintenance dan Just in time. Lean manufacturing adalah filosofi untuk mengurangi waktu antara pesanan pelanggan dan produk siap untuk pengiriman dengan menghilangkan waste/pemborosan[4]. Kasus dalam penelitian kaitannya lebih ditekankan kepada smoothing, dan Value Stream Map (VSM)[5] dalam Just-in-time, atau JIT, namun pada aktualnya beberapa rekomendasi yg dicantumkan membutuhkan program dasar dalam lean manufacturing seperti $5 \mathrm{R}$ yang penting untuk diterapkan [6]. JIT adalah metode manajemen persediaan di mana barang diterima dari 
A System Modelling Approach: Optimization Process and Machine Utilization in Production Plant Using Lean Manufacturing Simulation Model

pemasok hanya saat dibutuhkan. Penerapan metode ini bertujuan untuk mengurangi biaya penyimpanan persediaan dan meningkatkan perputaran persediaan [7], dan dalam analisis optimasi yang digunakan pada penelitian ini menggunakan simulasi model.

Salah satu faktor kegagalan dalam continuous improvement adalah aspek Implementation approach[8]. Oleh karenanya pada penelitian ini sebuah pendekatan Simulasi model dilakukan guna[9][10] muncul sebagai alat penting untuk mendukung pengambilan keputusan dan proses pemecahan masalah yang melekat dalam desain, manajemen, dan perbaikan berbagai jenis sistem operasi, termasuk manufaktur, logistik, kesehatan[11], maupun yang bersifat pengambilan keputusan finansial proyek[12]. Saat ini, simulasi adalah salah satu teknologi utama dalam kerangka konsep Industri 4.0. Konsep ini mendefinisikan organisasi baru pabrik (smart factory)[13], memungkinkan layanan pelanggan yang lebih baik melalui fleksibilitas yang sangat besar dan optimalisasi sumber daya. Beberapa prinsip utama dari penerapan Industri 4.0 adalah sebagai berikut:

1) Pabrik menjadi digital dan fleksibel, yang berarti terus menerus dan segera komunikasi antara berbagai stasiun kerja dan alat, terintegrasi ke dalam jalur produksi dan rantai pasokan;

2) Penggunaan alat simulasi dan pemrosesan data untuk mengumpulkan dan menganalisis data dari jalur perakitan yang digunakan untuk pemodelan dan pengujian. Ini adalah nilai yang bagus untuk karyawan yang ingin lebih memahami kondisi dan proses industry.

3) Pabrik menjadi lebih hemat dalam menggunakan energi dan sumber daya melalui penggunaan jaringan komunikasi untuk bertukar informasi secara terus menerus dan cara segera untuk mengkoordinasikan kebutuhan dan ketersediaan. Simulasi adalah kumpulan metode dan teknik, yang meliputi: diskrit, simulasi, simulasi berkelanjutan (termasuk dinamika sistem), Monte Carlo metode (termasuk simulasi statis dalam spreadsheet), permainan manajerial, kualitatif simulasi, simulasi agen, dan lain-lain.

Dalam penelitian ini, sebuah software FlexSim free version yang merupakan sebuah perangkat lunak simulasi terkemuka digunakan; beberapa kelebihan dari software ini antara lain; termasuk 3D terintegrasi pemodelan untuk representasi fisik yang realistis, terbuka dan mudah disesuaikan lingkungan pengembangan model, dan pembangunan logika berbasis proses untuk menentukan perilaku sistem yang kompleks dan interaksi objek [14] [15].

\section{Metode}

Metodologi pada penelitian ini mencakup proses pengumpulan data baik data sekunder dan data primer, tahap kedua yaitu analisis data dengan metode VSM sehingga diketahui berapa banyak NVA dan lead time existing.

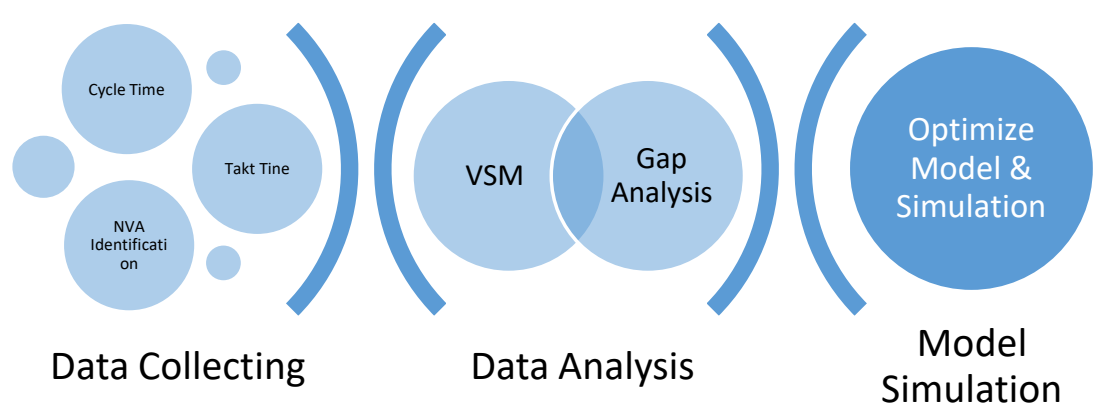

Gambar 2. Model metodologi penelitian 
Tahap berikutnya melakukan simulasi model dengan Flexsim sehingga didapat data uji simulasi yang lebih dinamis. Pada tahap ini beberapa uji skenario perbaikan dilakukan guna mengoptimalisasi proses.

\section{Hasil dan Pembahasan}

\subsection{Analisis value added VSM}

Berdasarkan analisis lead time total VSM yang telah dilakukan, didapat lead time 4.6 hari, dengan 9 SDM terpusat pada area melting, dan dengan takt time proses yang diminta oleh konsumen di plant helical adalah 27,6 sec. Dari analisis perbandingan antara waktu VA vs NVA diketahui bahwa terdapat unbalanced out proses di casting process, dimana hanya proses melting furnace yang mampu menyamai takt time konsumen, sedangkan proses hilir umumnya Pouring, bandsaw \& linish dan khususnya proses cooling time existing belum mampu menyamai takt time konsumen $(27,6 \mathrm{sec})$. Kehilangan waktu dalam menunggu proses pendinginan 1 jam (3600) menjadi bottleneck yang harus segera ditangani.

Tabel 1. Analisis perbandingan VA vs Takt time

\begin{tabular}{lccc}
\hline \multicolumn{1}{c}{ PROCESS STEP } & $\begin{array}{c}\text { VA work process } \\
\text { (sec) }\end{array}$ & $\begin{array}{c}\text { Takt Time } \\
\text { (sec) }\end{array}$ & $\begin{array}{c}\text { Work Takt } \\
\text { time }\end{array}$ \\
\hline MELTING & 0.049 & 27.6 & 0.002 \\
POURING + CURING & 168 & 27.6 & 6.07 \\
TIME & & & \\
COOLING TIME & 3,600 & 27.6 & 130.43 \\
BANDSAW & 106 & 27.6 & 3.84 \\
LINISH & 105 & 27.6 & 3.79 \\
\hline \multicolumn{1}{c}{ Total } & $\mathbf{3 , 9 7 8 . 3 8}$ & & \\
\hline
\end{tabular}

\subsection{Simulasi model kondisi eksisting}

Dari data VSM yang didapat, pengujian dan simulasi lanjutan dilakukan dengan menggunakan flexsim software, untuk menganalisis seberapa optimal proses saat ini secara simulasi. Pada uji simulasi digunakan kasus aktual proses berjalan yang menggunakan dengan 8 unit dies trolley, 3 Unit mesin t cutting, dan 3 unit linish. Dari hasil simulasi diketahui:

1) Tingkat utilisasi \& output per jam setiap mesin / proses cukup variatif:

a) Utilisasi Dies Trolley rata-rata $52,9 \%$, dengan rata-rata output $12,9 \mathrm{pcs} / \mathrm{jam}$

b) Utilisasi Mesin Cutting rata-rata 68\%, dengan rata-rata output 33,71 pcs/jam

c) Utilisasi Linish rata-rata $39,4 \%$, dengan rata-rata output $33,42 \mathrm{pcs} / \mathrm{jam}$

2) Loss time tinggi akibat idle 1 jam cooling time

3) Loss time waiting baik operator maupun transport

4) Kehilangan waktu dalam menunggu proses selanjutnya diakibatkan bottleneck proses didepannya.

5) Rework terjadi di setiap proses dikarenakan selain proses, juga beberapa defect casting baru terdeteksi ketika proses berjalan.

\subsection{Simulasi model meningkatkan optimasi utilisasi mesin}

Perubahan dilakukan secara incremental, beberapa perubahan pada future map awal ini antara lain:

1) Penguatan aktivitas 5R di lapangan

2) Relokasi layout plant casting untuk optimalisasi space. 
A System Modelling Approach: Optimization Process and Machine Utilization in Production Plant Using Lean Manufacturing Simulation Model

3) Standarisasi dokumentasi proses

4) Peningkatan efektivitas proses Pouring \& Curing Casting

a. Menggunakan dua operator dengan pembagian tugas 1 operator khusus pouring, dan satu operator lainnya bertugas memindahkan produk setelah proses curing time.

b. Menggunakan mesin mesin tilt pouring yang dimodifikasi dengan mekanisme semi auto open dies dengan timer, sehingga memangkas waktu utk eject produk, sekaligus mengurangi potensi reject casting.

5) Mengurangi waktu cooling time produk setelah proses curing. Dari rata-rata $3600 \mathrm{sec}$ menjadi $600 \mathrm{sec}$. Dengan menggunakan prinsip forced heat transfer melalui system electric fan blower yang bisa diset terhadap trolley yang berada di area casting.

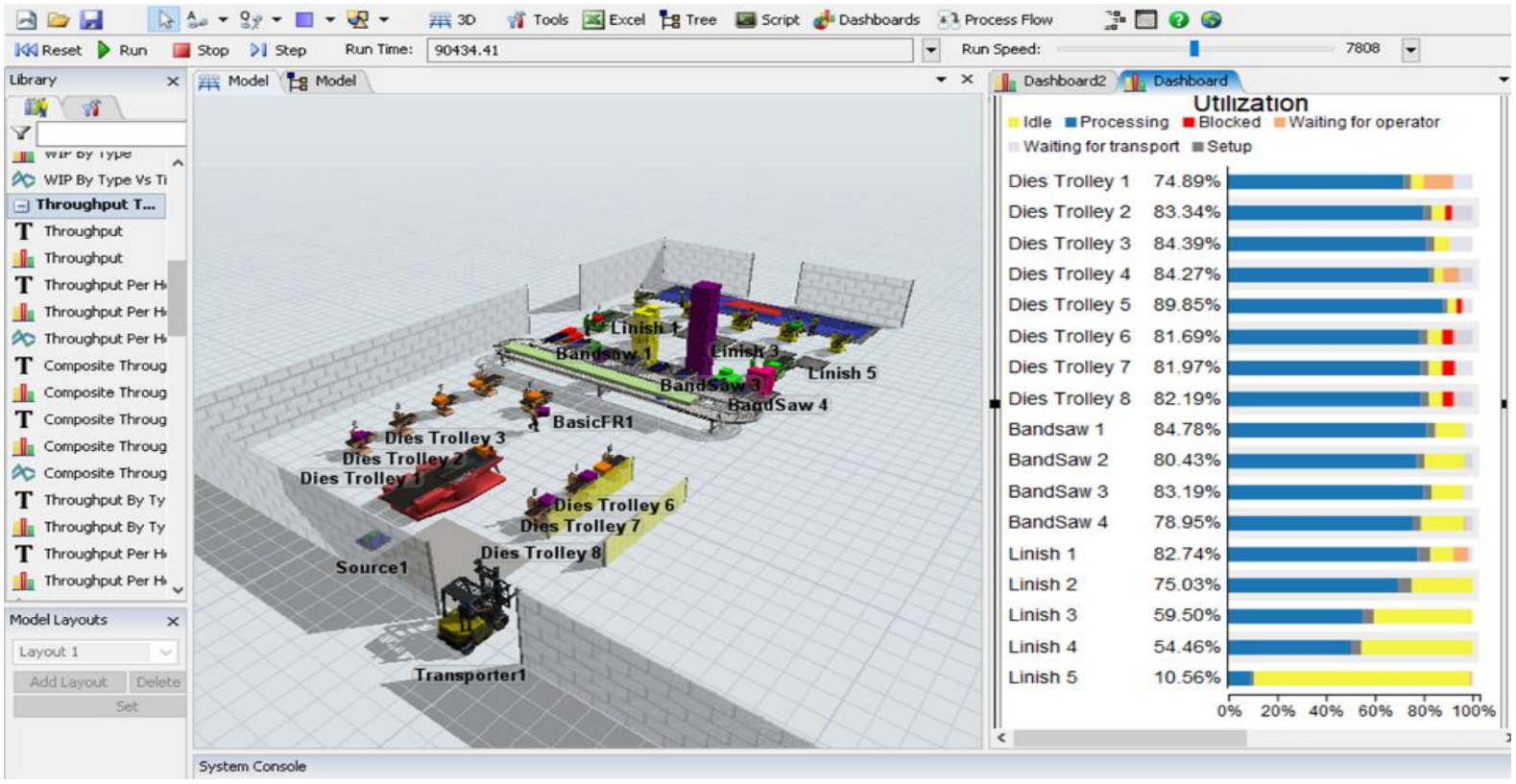

Gambar 3. Simulasi model tingkat utilisasi mesin dan proses line casting existing

\section{Utilization (\%)}

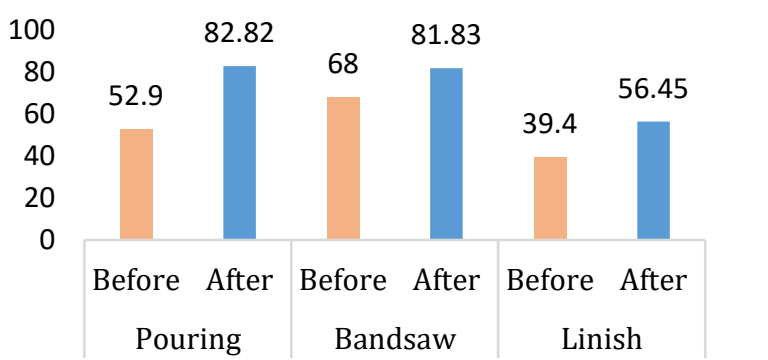

Average Ouput (Pcs/ hours)

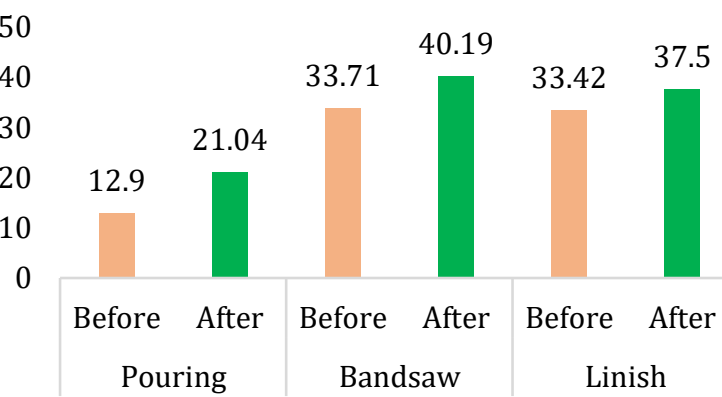

Gambar 4. Perbandingan before after improvement.

\section{Simpulan}

Perancangan perbaikan proses melalui pergantian alat potong pada jaw yang berfungsi sebagai pencengkram benda kerja mampu meningkatkan efisiensi biaya produksi $75.29 \%$ atau 
setara dengan nilai Rp. 1.111.211.971,61 dengan variabel biaya tenaga kerja $68.57 \%$, biaya proses operasi $81.02 \%$, biaya alat potong $46.81 \%$, serta biaya oli pendingin mencapai $50.00 \%$.

\section{Referensi}

[1] K. Perencanaan et al., "Covid-19, New Normal, dan Perencanaan Pembangunan di Indonesia," J. Perenc. Pembang. Indones. J. Dev. Plan., vol. 4, no. 2, pp. 240-252, 2020, doi: 10.36574/jpp.v4i2.118.

[2] S. Nazara, "Percepatan Pemulihan Ekonomi," p. 11, 2021, [Online]. Available: https://fiskal.kemenkeu.go.id/files/warta-fiskal/file/edisi-1-2021.pdf.

[3] Jeffrey K. Liker and Gary L. Convis, TOYOTA. Mc Graw Hill, 2012.

[4] M. Mayatra, N. D. Chauhan, and P. Trivedi, "A literature review on implementation of Lean Manufacturing Techniques," Int. J. Adv. Res. Ideas Innov. Technol., vol. 1, no. 4, pp. 4-10, 2015.

[5] A. Özkavukcu and M. B. Durmuşoğlu, "Production smoothing decisions with seasonal variation through value stream," 40th Int. Conf. Comput. Ind. Eng. Soft Comput. Tech. Adv. Manuf. Serv. Syst. CIE40 2010, pp. 9-11, 2010, doi: 10.1109/ICCIE.2010.5668163.

[6] H. MA Pahmi, "Implementasi 5R Sebagai Inisiatif Pondasi Improvement Awal Pada Perusahaan Pengolahan Pasir Silika," JENIUS J. Terap. Tek. Ind., vol. 1, no. 1, pp. 38-46, 2020, doi: 10.37373/jenius.v1i1.21.

[7] D. Shah and P. Patel, "Productivity Improvement by Implementing Lean Manufacturing Tools In Manufacturing Industry," Int. Res. J. Eng. Technol., vol. 5, no. 3, pp. 3794-3798, 2018.

[8] R. McLean and J. Antony, "Why continuous improvement initiatives fail in manufacturing environments? A systematic review of the evidence," Int. J. Product. Perform. Manag., vol. 63, no. 3, pp. 370-376, 2014, doi: 10.1108/IJPPM-07-2013-0124.

[9] P. Pawlewski, P. Hoffa-Dabrowska, P. Golinska, D. Karolina, and W.-L. Editors, FlexSim in Academe: Teaching and Research. 2019.

[10] P. Pawlewski and M. Anholcer, Using CSP Solvers as Alternative to Simulation Optimization Engines. Springer International Publishing, 2019.

[11] Y. R. Wang and A. N. Chen, "Production logistics simulation and optimization of industrial enterprise based on flexsim," Int. J. Simul. Model., vol. 15, no. 4, pp. 732-741, 2016, doi: 10.2507/IJSIMM15(4)C018.

[12] M. A. Pahmi and M. Imtihan, "Simulation to Optimized Logistic Model in Feasibility Assessment Dump Truck Investment," PVJ-IS 2020 Conf., pp. 1-6, 2020.

[13] B. Yan and D. Lee, "AS/RS simulation and optimization based on flexsim," 2009 Int. Work. Intell. Syst. Appl. ISA 2009, pp. 1-2, 2009, doi: 10.1109/IWISA.2009.5072759.

[14] W. B. Nordgren, "Flexsim simulation environment," Winter Simul. Conf. Proc., vol. 1, pp. 197-200, 2003, doi: 10.1109/wsc.2003.1261424.

[15] T. Liu and X. Ma, "The simulation research of distribution center sorting system based on flexsim," CSAE 2012 - Proceedings, 2012 IEEE Int. Conf. Comput. Sci. Autom. Eng., vol. 1, pp. 572-577, 2012, doi: 10.1109/CSAE.2012.6272662. 